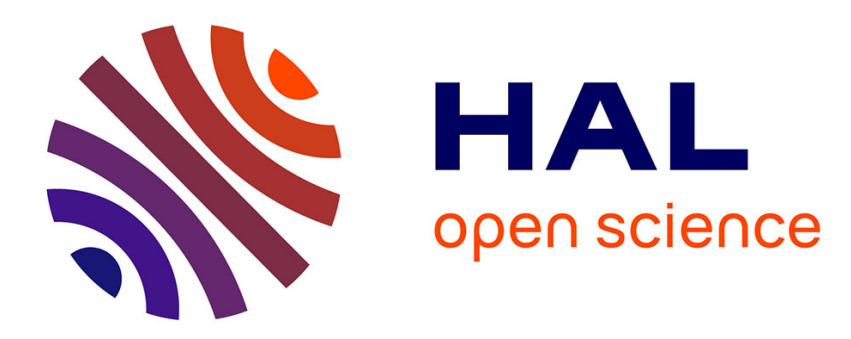

\title{
Medical Imaging in the Age of Artificial Intelligence
}

Nicholas Ayache

\section{To cite this version:}

Nicholas Ayache. Medical Imaging in the Age of Artificial Intelligence. Nordlinger B., Villani C., Rus D. Healthcare and Artificial Intelligence, Springer International Publishing, pp.89-91, 2020, 10.1007/978-3-030-32161-1_13. hal-02522507

\section{HAL Id: hal-02522507 \\ https://hal.inria.fr/hal-02522507}

Submitted on 3 Apr 2020

HAL is a multi-disciplinary open access archive for the deposit and dissemination of scientific research documents, whether they are published or not. The documents may come from teaching and research institutions in France or abroad, or from public or private research centers.
L'archive ouverte pluridisciplinaire HAL, est destinée au dépôt et à la diffusion de documents scientifiques de niveau recherche, publiés ou non, émanant des établissements d'enseignement et de recherche français ou étrangers, des laboratoires publics ou privés. 


\title{
Medical Imaging in the Age of Artificial Intelligence
}

\author{
Nicholas Ayache \\ in B. Nordlinger, C. Villani \& D. Rus (Editors), \\ Health and Artificial Intelligence, Springer 2020
}

Artificial intelligence is disrupting the world of medical imaging. Algorithms and models, already very present in the construction of medical images, are now powerful enough to guide the analysis of medical images as well as, if not better, human experts. These algorithms allow the construction of digital representations of the patient that guide diagnosis, prognosis and therapeutic management. On May 2, 2018, a symposium at the Collège de France brought together many experts on this subject. Their contributions are visible on the Collège ${ }^{1}$ website.

In dermatology, a deep convolutional network, previously trained on more than one-million natural images, was then adjusted with the images of 130,000 dermatological lesions, to learn to automatically distinguish cancerous lesions from benign ones as well as an expert dermatologist. In radiology, the French company Therapixel has developed a deep convolutional network with

1. Berry G. "Medical imaging and machine learning: towards an artificial intelligence?", https://www.college-de-france.fr/site/gerard-berry/ symposium-2017-2018.htm

2. Ayache N., "Digital Patient and Artificial Intelligence", Collège de France, 2 May 2018, https://www.college-de-france.fr/site/gerard-berry/symposium-2018-05-02-02-09h05.htm 
640,000 mammograms from a global challenge, and won the competition by distinguishing suspicious mammograms from normal ones better than all its competitors. Its software now surpasses the performance of expert radiologists. Finally, in ophthalmology, other deep convolutional networks, trained on more than 130,000 images of the retina, are able to detect diabetic retinopathy as well as an expert ophthalmologist. For the first time in history, software (IDx-DR) has been approved by the Food and Drug Administration (FDA) to make this diagnosis automatically without the image being seen by an ophthalmologist.

Even if these results are spectacular, they remain for the moment confined to specific, relatively narrow tasks, on which there are huge databases previously labelled by experts. However, these databases are not numerous, and their acquisition and especially their labelling by experts is very expensive. It is necessary to ensure that rare cases (which by definition are not numerous!) are well represented, that there is no bias (gender, age, ethnicity, etc.) and that there are enough healthy subjects (which poses an ethical problem when the imaging modality is irradiation, for example). Collecting such databases and making them available to learning algorithms also raises serious confidentiality issues.

Moreover, artificial intelligence is not limited to the development of deep convolutional networks, whose millions of parameters are difficult to interpret, and whose adjustment requires training on huge databases. There are a variety of classification algorithms that can be trained on databases of very variable sizes with very good results ${ }^{3}$. it is also possible to build numerical models of the patient that exploit all the knowledge we have in anatomy and physiology to limit ourselves to a reduced number of more easily interpretable biophysical parameters. Finally, the framework

3. Th i rion B. Introduction to Big Data Approaches to Medical Imaging", Collège de France, May 2, 2018, https://www.college-de-france.fr/site/gerard-berry/ symposium-2018-05-02-02-09h35.htm 
of the digital patient makes it possible to synthesize medical images that are realistic enough to train automatic learning systems, and then to transfer the learning to real images. Modern data-science methods also make it possible to take into account increasingly "holistic" data on the patient, including imaging data (structural and functional), but also biological data (genetic, metabolic, etc.) and even behavioral and environmental data (lifestyle, etc.). Thus, the UK-Biobank database plans to make all this data acquired on more than 100,000 participants available to the scientific community ${ }^{4}$. In France, a major project to collect image data associated with other biomedical data acquired on

a very large number of patients is being implemented in place at the AP-HP to serve the scientific communitys.

The field of application of artificial intelligence in medical imaging is intended to serve all medical disciplines. Without being exhaustive, we can already mention radiology, dermatology, ophthalmology, neurology, psychiatry, cardiology, senology, hepatology, endoscopy, endomicroscopy, anatomopathology, radiotherapy and image-guided surgery ${ }^{6}$. New legal issues are being raised

4. Nichols T., "Challenges and Opportunities in Population Neuroimaging", Collège de France, May 2, 2018, https://www.college-de-france.fr/site/gerard-berry/ symposium-2018-05-02-02-11h30.htm

5. Beauffret R., "The databank project of AP-HP", Collège de France, May 2, 2018, https://www.college-de-france.fr/site/ gerard-berry/symposium-2018-05-02-11h00.htm

6. Bertrand A., Durrleman S. and Epelbaum S. Neuroimaging, neurology and digital models for Alzheimer's disease", Collège de France,

May 2, 2018, https://www.college-de-france.fr/site/gerard-berry/symposium- 2018-05-0214h30.htm; Thomassin-Naggara I. and Clatz O., "Innovative technologies at the bedside of breast cancer screening: what future for women?", Collège de France, May 2, 2018, https://www.college-de-france.fr/ site/gerard-berry/symposium-2018-05-02-02-15h15.htm; Fournier L. "Radiomics applied to cancerology" Collège de France, 2 May 2018, https://www. college-de-france.fr/site/gerard-berry/symposium-2018-05-02-16h30__1.htm; Brady M., Some examples of transfers from laboratory to practice", Collège de France, 2 May 2018, https://www.collegede-france.fr/site/gerard-berry/ symposium-2018-05-02-17h30 1.htm 
by the emergence of these new decision-support softwares ${ }^{7}$, and questions are raised about the very future of certain medical specialties $^{8}$. All these applications and issues are also addressed in many other chapters of this book.

To conclude, I would like to stress that artificial intelligence and digital patient are a set of computer tools at the service of a "4 p" medicine: more personalized, precise, predictive and preventive in order to better treat the real patient. These new tools are intended to help doctors, not to replace them. Indeed, some of the physician's qualities such as compassion, comprehension, critical thinking and professional consciousness (the "4 $\mathrm{c}$ ") are still and for a long time the prerogative of human intelligence. They remain irreplaceable today.

7. Trick D. and Potter of the Varde B. "The lawyer's questions: what protections for patients and data?", Collège de France, 2 May 2018, https://www.college-de-france.fr/site/gerardberry/symposium-2018-05-02-12h00.htm

8. Besse F., "Why do radiologists have hopes and fears with Al", Collège de France, 2 May 2018, https://www.college-de-france.fr/site/ gerard-berry/symposium-2018-05-02-18h00.htm 